Archives de sciences sociales des religions

$164 \mid 2013$

Bulletin Bibliographique

\title{
Adam Possamaï (Ed.), Handbook of Hyper-real Religions
}

Leiden, Brill, 2012, 442 p.

Régis Dericquebourg

2 OpenEdition

Journals

Édition électronique

URL : http://journals.openedition.org/assr/25595

DOI : 10.4000/assr.25595

ISSN : $1777-5825$

Éditeur

Éditions de l'EHESS

Édition imprimée

Date de publication : 30 décembre 2013

Pagination : 274

ISSN : 0335-5985

Référence électronique

Régis Dericquebourg, «Adam Possamaï (Ed.), Handbook of Hyper-real Religions », Archives de sciences sociales des religions [En ligne], 164 | 2013, mis en ligne le 13 mars 2014, consulté le 21 septembre 2020. URL : http://journals.openedition.org/assr/25595; DOI : https://doi.org/10.4000/assr.25595

Ce document a été généré automatiquement le 21 septembre 2020

(C) Archives de sciences sociales des religions 


\section{Adam Possamaï (Ed.), Handbook of Hyper-real Religions}

Leiden, Brill, 2012, 442 p.

Régis Dericquebourg

\section{RÉFÉRENCE}

Adam Possamaï (Ed.), Handbook of Hyper-real Religions, Leiden, Brill, 2012, 442 p. 
1

Ce compendium marque la consécration de la notion de religion hyper-réelle qu'Adam Possamaï avait présentée en 2005 dans un ouvrage précédent: Religion and Popular Culture: A hyper-real Testament (Bruxelles, Peter Lang) et que nous avions recensé dans le Bulletin bibliographique des ASSR (2006, 136-89). Pour l'auteur, une religion hyper-réelle est « un simulacre de religion créée ou en symbiose avec une religion populaire qui inspire sur le plan métaphorique et/ou qui est la source de croyances pour la vie quotidienne ". La notion d'hyper-réalité appartient à la pensée de Baudrillard, mais chez Adam Possamaï, elle renvoie à la culture populaire de bande dessinée et surtout aux réseaux qui se forment sur internet. Il s'y forme des communautés virtuelles dont les participants affirment s'inscrire dans une démarche spirituelle. L'auteur distingue trois sous-types d'acteurs des religions hyper-réelles: les consommateurs actifs de culture populaire qui conduisent aux religions hyper-réelles (ce sont les créateurs de religions comme celles du Jedi ou de Matrix ou des gens qui enrichissent des spiritualités existantes comme le paganisme), des consommateurs occasionnels de culture populaire qui se servent de celles-ci pour enrichir leur religion d'origine (comme les chrétiens gothiques), les acteurs religieux ou athées (secular) opposés aux religions hyper-réelles (comme les chrétiens fondamentalistes). Ce troisième sous-type se spécifie donc comme un type en réaction contre les religions hyper-réelles.

Il n'est pas possible de présenter la vingtaine de chapitres de ce « Handbook ». Tantôt, ils discutent et tantôt ils illustrent la notion de religion hyper-réelle. Cela va d'une étude du Ramayama revisité par les auteurs d'une série télévisée indienne populaire qui s'inscrivait dans la renaissance du nationalisme hindou (Cuzak) à l'article de Massimo Introvigne qui met en doute la nouveauté du Da Vinci Code en tant que genre littéraire (il appartiendrait à la veine littéraire des feuilletons) en passant par les «jeux informatisés » chrétiens (Bernauer, Walliss), ou encore par une présentation du Hiphop musulman (Nasir). On trouve aussi des interprétations de l'apparition de ces nouvelles manières de croire comme celle de Stef Aupers qui impute l'origine de ces spiritualités à l'érosion des grands courants chrétiens. Tous les articles sont intéressants et apportent une réflexion utile sur la construction théorique d'A. Possamaï. Vu leur nombre, consacrer quelques lignes à chacun transformerait notre recension en une note de lecture. Nous regrettons donc de ne pas pouvoir les mentionner toutes. Elles présentent l'intérêt de faire découvrir ces spiritualités. Les plus remarquables sont celles qui sont nées grâce à l'internet dont l'utilisation par le public remonte seulement à 1990 avec une expansion commerciale en 1995. De ce point de vue, les séries religieuses télévisées comme le Ramayana apparaissent déjà vieilles par rapport aux réseaux interactifs des disciples du Jedi. Toutefois, leurs publics 
respectifs avouent qu'ils vivent une expérience religieuse. La mise en perspective des nouveaux véhicules de la spiritualité montre que l'imagination religieuse est toujours à l'œuvre dans toutes les cultures et qu'elle est portée par une énergie créatrice. Nous ouvrirons la discussion en reprenant, avec Martin Goeffroy, le lien entre l'auteur et J. Baudrillard. Nous l'avons dit plus haut : pour le premier, les religions hyper-réelles sont des simulacres de religion. Par «religion" il faut sans doute comprendre "Confessions établies et reconnues ». Cette affirmation a sa source dans les thèses de J. Baudrillard sur la culture. Celle-ci serait dominée par la simulation. Cela signifie qu'il n'y aurait plus de différence entre l'objet et sa représentation. La différence entre les deux auteurs réside dans le fait que chez Baudrillard les grandes Confessions sont aussi hyper-réelles. Nous sommes alors conduits à poser en conclusion cette question : si les religions hyper-réelles sont un simulacre de religion, de quoi les grandes confessions considérées comme "authentiques» sont-elles le simulacre? En quoi les "récits mythiques » qui fondent les "grandes religions » seraient-elles moins mythiques et moins littéraires que les spiritualités fondées sur les écrits de Tolkien, sur Matrix et sur Starwars ? Finalement, la question rappelle celle qui s'est posée à propos du bricolage religieux. Des sociologues ont employé cette expression pour spécifier des idéologies et des pratiques du Nouvel Âge. Mais par comparaison, cela nous a conduits à constater qu'il n'y a pas de religion pure et homogène descendue du ciel et que nous découvrons des bricolages dans lesdites « Traditions religieuses». 